\title{
A re-analysis of the molecular phylogeny of Lacertidae with currently available data
}

\author{
Paschalia Kapli ${ }^{1,2 *}$, Nikos Poulakakis ${ }^{1,2}$, Petros Lymberakis ${ }^{1}$, Moysis Mylonas ${ }^{1,2}$ \\ ${ }^{1}$ Natural History Museum of Crete, University of Crete, Irakleio, Crete, Greece. \\ ${ }^{2}$ Department of Biology, University of Crete, Irakleio, Crete, Greece. \\ * Correspondence: University of Crete, Natural History Museum of Crete, Knossos Avenue, Postal Code 71409 P.O. 2208, Iraklio, \\ Crete, Greece. Phone and Fax: +30 28103324366. E-mail: k.pashalia@gmail.com
}

Received: 11 April 2011; received in revised form: 3 August 2011; accepted: 5 September 2011.

The Lacertidae is one of the most diverse and widespread lizard families throughout Eurasia and Africa. Several studies so far have attempted to unravel the phylogeny of Lacertidae using morphological and molecular data. However, the intra-family relationships remain unclear. In an effort to explore the phylogenetic relationships within the family Lacertidae, a concatenated dataset of $5727 \mathrm{bp}$ from six genes (two nuclear and four mitochondrial) and 40 genera was assembled based on GenBank database. Phylogenetic inference analyses were conducted using Maximum Parsimony (MP), Bayesian inference (BI) and Maximum Likelihood (ML), revealing that even a combined dataset of both mitochondrial and nuclear genes is not able to resolve the phylogenetic relationships of the Lacertidae family under the tribe level.

Key words: GenBank; Lacertidae; phylogeny.

Reanálisis de la filogenia molecular de los Lacertidae usando los datos disponibles en la actualidad. La familia Lacertidae es una de las más diversas y ampliamente distribuidas en Eurasia y África. Varios estudios han intentado hasta ahora aclarar la filogenia de los Lacertidae usando datos morfológicos y moleculares. Sin embargo, las relaciones dentro del grupo permanecen poco claras. En un esfuerzo por explorar las relaciones filogenéticas dentro de la familia Lacertidae, se analizó una base de datos de 5727 pares de bases para 40 géneros diferentes de lacértidos obtenidos por la concatenación de seis genes (dos nucleares y cuatro mitocondriales), todos ellos disponibles en la base de datos de GenBank. Los análisis filogenéticos realizados usando métodos de máxima parsimonia (MP), inferencia bayesiana (BI) y máxima verosimilitud (ML), revelaron que el conjunto combinado de genes mitocondriales y nucleares utilizados no es capaz de resolver las relaciones filogenéticas de los lacértidos a un nivel taxonómico inferior al de tribu.

Key words: filogenia; GenBank; Lacertidae.

Lacertidae is a family of small body sized lizards distributed throughout Eurasia and Africa. In recent years this family has been the subject of several taxonomical studies, considering both molecular and morphological characters. ARNOLD (1989), based on morphological characters, constructed the phylogeny of this family and proposed the division of the Lacertidae into two subgroups, the "Primitive
Palearctic and Oriental Lacertids" and the "Ethiopian and Advanced Saharo-Eurasian forms". A series of studies (LUTZ \& MAYER, 1984, 1985; MAYER \& BENYR, 1995) based on albumin-immunology, resulted in the establishment of two subfamilies, Gallotiinae, which includes two genera, Gallotia and Psammodromus, and Lacertinae including the rest of the Lacertidae family. HARRIS et al. (1998) and FU 
(1998, 2000) used mitochondrial DNA sequences to explore the relationships of lacertid lizards. However, in all cases, the datasets were insufficient to reconstruct the intra-family phylogeny of Lacertidae. In the same study, HARRIs et al. (1998) combined morphological characters along with molecular data and led to the division of the family into three subfamilies: 1) Gallotiinae, 2) Lacertinae and 3) Eremiainae. The first two correspond to ARNOLD's (1989) "Primitive Palearctic and Oriental Lacertids", while Eremiainae is equivalent to the "Ethiopian and Advanced Saharo-Eurasian forms" and to ARNOLD's (1973) “armatured” clade. A recent work of MAYER \& PAVLICEV (2007) confirmed the division in subfamilies proposed by HARRIS et al. (1998) and indicated the division of the subfamily Eremiainae into two clades, "Ethiopian" and "Saharo-Eurasian". ARNOLD et al. (2007) downgraded Lacertinae and Eremiainae into tribes (i.e. Lacertini and Eremiadini, respectively) of the subfamily Lacertinae. PAVLICEV \& MAYER (2009) argued that the use of the tribe as a taxonomic entity causes confusion while they concluded that the polytomy of Lacertini is more likely to be attributed to multiple cladogenesis in a geologically short time than to the poor resolution of the markers used. Despite PAVLICEV \& MAYER (2009) opinion, in the current study we follow the systematics proposed by ARNOLD et al. (2007) since it is more descriptive of the phylogeny of the family.

The aim of this study was to reassess the phylogeny of the family using all currently available data from GenBank. Primarily the data used here were produced by the molecular studies mentioned before and concluded in a dataset of four mitochondrial and two nuclear genes from 40 genera.

\section{MATERIALS AND METHODS}

Published sequences were retrieved from GenBank (four mitochondrial genes: 16S rRNA, 12S rRNA, cyt b, and COI, and two nuclear genes: c-mos and RAG-1). We built a concatenated dataset in which each genus is represented by one chimerical sequence of the six genes (all accession numbers are given in Table 1).

All genes were identified and the corresponding sequences were saved to individual FASTA-formatted files for each gene. The poorly aligned positions for the genes $12 S$ rRNA and 16S rRNA were removed using the online version of Gblocks (V. 0.91b, Castresana, 2000) under the less stringent options ( 412 bp out of 1455 bp and 168 bp out of $1010 \mathrm{bp}$ were removed for $16 \mathrm{~S}$ rRNA and $12 \mathrm{~S}$ rRNA, respectively). The final dataset was comprised of 5727 bp for 40 Lacertidae genera. Representative sequences from the genus Eumeces (chimerical sequence out of the species $E$. anthracinus, E. ergegius and E. inexpectatus) were added to each data set as outgroup.

\section{Phylogenetic analyses}

The Bayesian Information Criterion (BIC) as implemented by jModeltest (v.0.1.1; POSADA, 2008), was used to choose the best-fit model of DNA substitution. The best fit models (among 88 available) for $12 \mathrm{~S}$ rRNA, 16S rRNA, COI, cyt b, rag1 and c-mos were: TPM1 uf $+\mathrm{I}+\mathrm{G}$, TPM2uf $+\mathrm{G}$, TIM $2+\mathrm{I}+\mathrm{G}$, TPM2uf $+\mathrm{G}$, Trn $+\mathrm{I}+\mathrm{G}$ and $\mathrm{K} 80+\mathrm{G}$, respectively. For the BI analysis in the cases where the model selected by jModeltest could not be implemented the closest more complica- 
Table 1: List of sequences used in the analyses. Genera name and GenBank accession numbers for each gene included in the analyses are provided (12S, 16S, cyt b, CO1, rag1 and c-mos). Sequences that were not available in GenBank are indicated as n/a.

\begin{tabular}{|c|c|c|c|c|c|c|}
\hline \multirow[t]{2}{*}{ Genera } & \multicolumn{6}{|c|}{ GenBank accession numbers } \\
\hline & $12 S$ & $16 s$ & Cyt b & CO1 & c-mos & Rag1 \\
\hline Gallotia & AF206587 & AF206587 & AF101224 & AF206562 & EF632260 & EF632215 \\
\hline Psammodromus & AF206588 & AF206588 & AF206535 & AF206567 & EF632284 & $\mathrm{n} / \mathrm{a}$ \\
\hline Acanthodactylus & AF206607 & AF206607 & AF206536 & AF206568 & EF632252 & EF632207 \\
\hline Adolfus & AF206615 & AF206615 & AF206539 & AF206578 & EF632253 & EF632208 \\
\hline Algyroides & AF206598 & AF206598 & AF206529 & AF206557 & EF632255 & EF632210 \\
\hline Anatololacerta & AJ238188 & GQ142107 & DQ461765 & $\mathrm{n} / \mathrm{a}$ & DQ461743 & EF632224 \\
\hline Dalmatolacerta & AF440601 & AF440616 & AY278199 & $\mathrm{n} / \mathrm{a}$ & EF632271 & EF632228 \\
\hline Darevskia & AF206597 & AF206193 & U88611.3 & AF206552 & EF632257 & EF632212 \\
\hline Dinarolacerta & AF440600 & AF440615 & GQ142141 & $\mathrm{n} / \mathrm{a}$ & EF632270 & EF632227 \\
\hline Eremias & AF206604 & AF206604 & AF206549 & AF206576 & EF632259 & EF632214 \\
\hline Heliobolus & AF206608 & AF206608 & AF206544 & AF206583 & EF632262 & EF632217 \\
\hline Hellenolacerta & AF440602 & AF440617 & GQ142128 & $\mathrm{n} / \mathrm{a}$ & EF632269 & EF632225 \\
\hline Iberolacerta & AF440598 & AF440612 & AY267242 & AF206571 & EF632264 & EF632219 \\
\hline Latastia & AF206609 & AF206609 & AF206545 & AF206563 & EF632272 & EF632229 \\
\hline Meroles & AF206610 & AF206611 & AF206540 & AF206581 & EF632273 & EF632230 \\
\hline Mesalina & AY035832 & AF206606 & FJ416173 & AF206580 & EF632274 & EF632232 \\
\hline Nucras & AF206612 & AF206612 & AF206550 & AF206565 & EF632276 & EF632233 \\
\hline Atlantolacerta & AF206603 & AF149945 & AF206537 & AF206579 & GQ142144 & GQ142154 \\
\hline Ophisops & AF206605 & AF206605 & AF206532 & AF206556 & EF632278 & EF632235 \\
\hline Parvilacerta & AJ238187 & GQ142106 & GQ142135 & $\mathrm{n} / \mathrm{a}$ & EF632279 & EF632236 \\
\hline Pedioplanis & AF206613 & AF206613 & AF206546 & AF206566 & EF632280 & EF632237 \\
\hline Poromera & AF080368 & AF080370 & AF080369 & $\mathrm{n} / \mathrm{a}$ & EF632283 & EF632240 \\
\hline Tropidosaura & AF206616 & AF206616 & AF206541 & AF206582 & EF632291 & EF632248 \\
\hline Ichnotropis & AF080365 & DQ871149 & AF080366 & $\mathrm{n} / \mathrm{a}$ & EF632266 & EF632221 \\
\hline Phoenicolacerta & NC_011606 & NC_011606 & DQ461762 & NC_011606 & DQ461740 & EF632226 \\
\hline Takydromus & AB0̄080237 & $\mathrm{AB} 080237$ & AB080237 & AF206558 & EF632288 & EF632245 \\
\hline Teira & AJ004884 & GQ142096 & GQ142121 & AF372052 & EF632289 & EF632246 \\
\hline Timon & AF206595 & AF206595 & DQ902142 & AF206569 & EF632290 & EF632247 \\
\hline Zootoca & AF206594 & AF206594 & AY714929 & AF206554 & EF632292 & EF632249 \\
\hline Apathya & AF145444 & AF149946 & GQ142127 & unpublished & EF632268 & EF632223 \\
\hline Scelarcis & AF206602 & AF206602 & AF206538 & AF206570 & GQ142145 & GQ142155 \\
\hline Omanosaura & AF080347 & AF080352 & AF080351 & $\mathrm{n} / \mathrm{a}$ & EF632277 & EF632234 \\
\hline Lacerta & AM176577 & AM176577 & AM176577 & AF206551 & EF632267 & EF632222 \\
\hline Podarcis & AF206601 & AF206601 & AY234154 & AF206575 & EF632282 & EF632239 \\
\hline Australolacerta & FR751396 & FR751396 & FR751398 & $\mathrm{n} / \mathrm{a}$ & $\mathrm{n} / \mathrm{a}$ & DQ871208 \\
\hline Holaspis & $\mathrm{n} / \mathrm{a}$ & $\mathrm{n} / \mathrm{a}$ & $\mathrm{n} / \mathrm{a}$ & $\mathrm{n} / \mathrm{a}$ & EF632263 & EF632218 \\
\hline Iranolacerta & GQ142088 & GQ142111 & GQ142140 & $\mathrm{n} / \mathrm{a}$ & GQ142152 & GQ142162 \\
\hline Philochortus & $\mathrm{n} / \mathrm{a}$ & $\mathrm{n} / \mathrm{a}$ & $\mathrm{n} / \mathrm{a}$ & $\mathrm{n} / \mathrm{a}$ & EF632281 & EF632238 \\
\hline Psenderemias & $\mathrm{n} / \mathrm{a}$ & $\mathrm{n} / \mathrm{a}$ & $\mathrm{n} / \mathrm{a}$ & $\mathrm{n} / \mathrm{a}$ & EF632286 & EF632243 \\
\hline Archaeolacerta & AF206592 & AF206592 & GQ142126 & $\mathrm{n} / \mathrm{a}$ & EF632256 & EF632211 \\
\hline Scincidae & NC_000888 & NC_000888 & NC_000888 & NC_000888 & AY217888 & AY662634 \\
\hline
\end{tabular}


ted model was used (RONQUist \& HUELSENBECK, 2003).

Phylogenetic inference analyses were conducted using Bayesian Inference (BI), Maximum Parsimony (MP) and Maximum Likelihood (ML). Nucleotides were used as discrete, unordered characters. BI analysis was performed in MrBayes (v3.1; RONQUIST \& HuelSENBECK, 2003), with partitioned dataset by genes, using the models discussed above. The analysis was run four times with eight chains for $10^{7}$ generations and the current tree was saved to file every $10^{2}$ generations. This generated an output of $10^{5}$ trees for every run. The $-\operatorname{lnL}$ stabilized after approximately $10^{4}$ generations, thus the first $10^{4}$ trees $(10 \%$ "burn-in" in Bayesian terms) of every run were discarded as a conservative measure to avoid the possibility of including random, suboptimal trees. The percentage of samples recovering any particular clade in a BI analysis represents that clade's posterior probability (HuelsenbeCK \& RonQuist, 2001). A majority rule consensus tree ('Bayesian' tree) was then calculated from the posterior distribution of trees, and the posterior probabilities calculated as the percentage of samples recovering any particular clade (HUELSENBECK \& RONQUIST, 2001), where probabilities $\geq 95 \%$ indicate significant support.

MP analysis was performed with PAUP* v.4.0b10 (SWOFFORD, 2002). This analysis was carried out (heuristic searches) using stepwise addition and performing tree bisection-reconnection (TBR) branch swapping (SWOFFORD et al., 1996). Confidence in the nodes of MP trees was assessed by 1000 bootstrap replicates (FELSENSTEIN, 1985). The analysis was run twice with the gap considered as missing and as a fifth character.
Finally ML analysis was performed in the online version of RaxML (STAMATAKIS et al., 2008) using a mixed partitioned model and the following parameters: $\alpha$-shape parameters, GTR-rates, and base frequencies estimated and optimized for each partition (gen). Furthermore, gamma model of rate heterogeneity was assumed for all partitions while the invariable sites were estimated by the analyses. Confidence in the nodes of ML trees was assessed by 100 bootstrap replicates.

\section{Soft vs. hard molecular polytomies}

Unresolved evolutionary relationships are considered soft polytomies in that they are multiple dichotomous branching events occurring in rapid succession. To differentiate between poorly supported clades (soft polytomies) vs. zero-length branches (hard polytomies), we used the likelihood ratio test $\left[-2\left(\ln L_{\mathrm{Ha}}-\ln L_{\mathrm{Ho}}\right)\right]$, proposed by SLOWINSKI (2001), where $L_{\mathrm{Ha}}$ is the likelihood under the alternate hypothesis (the length of branch in question is nonnegative) and $L_{\mathrm{Ho}}$ is the likelihood under the null hypothesis (branch has zero-length). Using the 'describe trees' command following our ML run (with 'Perform likelihood-ratio test for zero branch lengths' selected in the likelihood settings menu), PAUP* calculated the probability for each likelihood ratio under the $\chi^{2}$ distribution with one degree of freedom. Significance for the likelihood ratio test for each branch in the phylogeny was determined using the percentage point values under the GOLDMAN \& WHELAN (2000) mixed model. We used $\alpha=0.05$ as significance level to account for possible Type I error. 


\section{RESULTS}

Of the 5727 sites examined, 2557 were variable, 1860 of which were parsimony informative (2690 and 1945 respectively, when the outgroup was included). The MP analysis when the gap was considered as missing produced one tree with a length of 13941 steps, while three equally parsimonious trees with a length of 14361 steps were produced when the gap was treated as a fifth character. The topologies recovered were the same for most of the clades (differences are discussed below).

BI resulted in the topology shown in Fig.1 (identical topologies were recovered for each of the four runs). All analyses recognized the division of the family in two main clades (Gallotiinae and Lacertinae) and the division of the later in two subclades (Lacertini and Eremiadini) with strong statistical support. In the case of Lacertini no analyses managed to resolve the relationships among the 20 genera under study. One monophyletic group within Lacertini was recognized by all analyses (Teira and Scelarcis) while Algyroides and Dinarolacerta formed a monophyletic clade for BI and ML, whereas for MP only when the gap was considered as a fifth character. ML supported a sister relationship of the later with Iberolacerta (62\% bootstrap support) while for MP when the gap was treated as a fifth character another monophyletic group (Lacerta and Timon) was supported (51\% bootstrap support). In the case of Eremiadini, MP (either when the gap was treated as missing or as a fifth character) could not resolve adequately the relationships of the taxa under study. On the contrary BI and ML resulted in the same topology with the exception that ML supported a basal position of Pedioplanis for the clade including Meroles, Ichnotropis, Tropidosaura and Australolacerta. Finally the unresolved relationships of the family, according to the likelihood ratio test (SLOWINSKI, 2001), could be considered as soft polytomies with the exception of the branch length separating Poromera ( $\alpha>0.05$, Fig. 1).

\section{DISCUSSION}

The genera comprised in the Eremiadini tribe (ARNOLD et al., 2007) form a subclade within Lacertinae in all analyses. This clade showed significant internal structure into

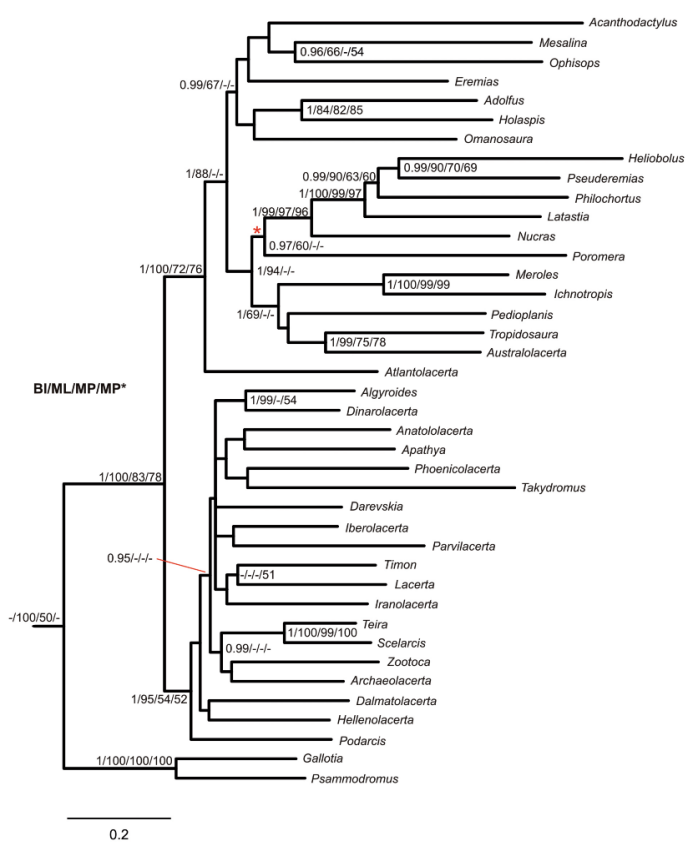

Figure 1: Phylogenetic relationships among the 40 genera included in the analyses as inferred by BI. Bayesian posterior probability values $(>0.95)$ are presented on the nodes followed by bootstrap values (> 50\%) for ML, MP and MP* (considering the gap as a fifth character). Branch lengths statistically not significantly greater than zero are indicated with an asterisk $\left.{ }^{*}\right)$. Eumeces anthracinus, E. ergegius and $E$. inexpectatus (Scincidae) were used as outgroup (not shown). 
three groups, two of which correspond to the division of MAYER \& PAVLICEV's (2007) 'Ethiopian' and 'Saharo-Eurasian', while Atlantolacerta appears as basal in accordance with ARNOLD et al. (2007). Surprisingly the Ethiopian group, which includes most of the least studied genera of Lacertidae (SALVI et al., 2011), appeared as the best resolved clade of the family. It is worth noticing that the sister relationship of Australolacerta and Tropidosaura proposed recently by SALVI et al. (2011) is also confirmed by this study.

The genera that belong to the Lacertini tribe appear as a monophyletic clade in all analyses with strong statistical support, although relationships within the clade have low resolution. It is interesting to note that two monophyletic clades were recognized by all analyses, Scelarcis with Teira and Dinarolacerta with Algyroides (Fig. 1). For the first case PAVLICEV \& MAYER (2009) propose that these two genera should be united in one, while the case of Dinarolacerta with Algyroides remains puzzling until further data for the taxa will be available. The problem of reconstructing the phylogenetic relationships within Lacertini arose in all previous studies (HARRIs et al., 1998; FU, 2000; ARnold et al., 2007; Mayer \& PAVliceV, 2007, PAVliceV \& MaYer, 2009) with different datasets. Here we show that neither a dataset of 5727 bp (two nuclear and four mitochondrial genes) with a wide genera sampling is able to shed light in the relationships between Lacertini. According to the most recent molecular phylogeny of the taxon (Pavlicev \& MaYer, 2009) it was assumed that the poor resolution was more likely to reflect a rapid radiation resulting in a polytomy than considering the markers used inappropriate. The results of the likelihood ratio test, conducted for the current dataset, suggest that the unresolved relationships of both Eremiadini and Lacertini are more likely to be seen as a case of a soft polytomy. Hence before the rejection or acceptance of PAVLICEV \& MAYER's (2009) view, two aspects could be further researched: 1) taxa sampling and 2) quantity/quality of genetic markers. As far as the first is concerned, even though Lacertidae has been the subject of several studies, the intra genera variation in most of the cases remains unexplored. Taking this under consideration it could be assumed that the unresolved relationships of the family could be attributed to inadequate data sampling. For the near future, analyses with more species per genus could show improvement in case we are facing a 'soft' and not a 'hard' polytomy of Lacertini. Furthermore it should be taken into account that if we assume 'hard' polytomy for Lacertini the same hypothesis should be extended, to some degree, to Eremiadini since the relationships among some of its genera remain unresolved.

Regarding the amount and the combination of the particular genetic markers there should not be a problem of too much or too little variation, as stated before (PAVLICEV \& MAYER, 2009). Nevertheless the combination of multiple genes phylogeny (i.e. complete mtDNA genome) or the application of restriction site-associated DNA tags (RAD tags, BAIRD et al., 2008, EMERSON et al., 2010) could be interesting approaches that could provide much more detailed and extensive information. Also the investigation for RGCs (Rare Genomic Changes) that have become increasingly important in systematics and 
complement phylogenetic analyses of primary sequence data, as noted by SPRINGER et al. (2004), could ultimately provide the most convincing resolution of intra-Eremiadini and -Lacertini phylogeny.

Summarizing the above we can assume that analyses based on the current available data are able to resolve the phylogenetic relationships on the level of subfamily and tribe. However, resolution of the relationships below the tribe level in Eremiadini and Lacertini necessitates a more sophisticated analysis and better knowledge on the intra genera variation.

\section{REFERENCES}

ArNOLD, E.N. (1973). Relationships of the Palearctic lizards assigned to the genera Lacerta, Algyroides and Psammodromus (Reptilia: Lacertidae). Bulletin of the British Museum (Natural History), Zoology 25: 291-366.

ARNOLD, E.N. (1989). Towards a phylogeny and biogeography of the Lacertidae: Relationships within an Old-World family of lizards derived from morphology. Bulletin of the British Museum (Natural History), Zoology 55: 209-257. Arnold, E.N.; Arribas, O. \& Carranza, S. (2007). Systematics of the Palaearctic and Oriental lizard tribe Lacertini (Squamata: Lacertidae: Lacertinae), with descriptions of eight new genera. Zootaxa 1430: 1-86. BAird, N.A.; ETTER, P.D.; ATwOOD, T.S.; Currey, M.C.; Shiver, A.L.; LeWIS, Z.A.; SelKer, E.U.; Cresko, W.A. \& JoHnson, E.A. (2008). Rapid SNP discovery and genetic mapping using sequenced RAD markers. PLoS ONE 3: e3376.
Castresana, J. (2000). Selection of conserved blocks from multiple alignments for their use in phylogenetic analysis. Molecular Biology and Evolution 17: 540-552.

Emerson, K.J.; Merz, C.R.; Catchen, J.M.; Hohenlohe, P.A.; Cresko, W.A.; Bradshaw, W.E. \& Holzapfel, C.M. (2010). Resolving postglacial phylogeography using high-throughput sequencing. Proceedings of the National Academy of Sciences of the United States of America 107: 16196-16200.

Felsenstein, J. (1985). Confidence limits on phylogenies: an approach using the bootstrap. Evolution 39: 783-791.

FU, J. (1998). Toward the phylogeny of the family Lacertidae: Implications from mitochondrial DNA $12 \mathrm{~S}$ and $16 \mathrm{~S}$ gene sequences (Reptilia: Squamata). Molecular Phylogenetics and Evolution 9: 118-130.

FU, J. (2000). Toward the phylogeny of the family Lacertidae - Why 4708 base pairs of mtDNA sequences cannot draw the picture. Biological Journal of the Linnean Society 71: 203-217.

Goldman, N. \& Whelan, S. (2000). Statistical tests of gamma-distributed rate heterogeneity in models of sequence evolution in phylogenetics. Molecular Biology and Evolution 17: 975-978.

Harris, D.J.; Arnold, E.N. \& ThOMAS, R.H. (1998). Relationships of lacertid lizards (Reptilia: Lacertidae) estimated from mitochondrial DNA sequences and morphology. Proceedings of the Royal Society B 265: 1939-1948.

Huelsenbeck, J.P. \& Ronquist, F. (2001). MRBAYES: Bayesian inference of phylogenetic trees. Bioinformatics 17: 754-755. 
LuTZ, D. \& MAYER, W. (1984). Albuminimmunologische und proteinelektrophoretische Untersuchugen zur systematischen Stellung von Lacerta lepida Daudin und Lacerta princeps Blanford (Sauria, Lacertidae). Zoologischer Anzeiger 212: 95-104.

LuTZ, D. \& MAYER, W. (1985). Albumin evolution and its phylogenetic implications in several lacertid lizards. AmphibiaReptilia 6: 53-61.

MAYeR, W. \& Benyr, G. (1995). Albuminevolution und phylogenese in der familie Lacertidae. Annalen des Naturhistorischen Museums in Wien 96 B: 621-648.

Mayer, W. \&PAVlicev, M. (2007). The phylogeny of the family Lacertidae (Reptilia) based on nuclear DNA sequences: convergent adaptations to arid habitats within the subfamily Eremiainae. Molecular Phylogenetics and Evolution 44: 1155-1163.

Pavlicev, M. \& Mayer, W. (2009). Fast radiation of the subfamily Lacertinae (Reptilia: Lacertidae): History or methodical artefact? Molecular Phylogenetics and Evolution 52: 727-734.

PosAdA, D. (2008). jModelTest: Phylogenetic model averaging. Molecular Biology and Evolution 25: 1253-1256.

RonQuist, F. \& HueLSENBECK, J.P. (2003).
MRBAYES 3: Bayesian phylogenetic inference under mixed models. Bioinformatics 19: 1572-1574.

Salvi, D.; Bombi, P. \& Vignoli, L. (2011). Phylogenetic position of the Southern Rock Lizard Australolacerta australis within the Lacertidae radiation. African Journal of Herpetology 60: 60-69.

SLOWINSKI, J.B. (2001) Molecular polytomies. Molecular Phylogenetics and Evolution 19: 114-120.

Springer, M.S.; Stanhope, M.J.; MAdSen, O.; Wilfried, W. \& DE Jong, W.W. (2004). Molecules consolidate the placental mammal tree. Trends in Ecology and Evolution 19: 430-438.

STAMATAKIS, A.; HoOver, P., \& Rougemont, J. (2008). A rapid bootstrap algorithm for the RAxML Web servers. Systematic Biology 75: 758-771.

SwofFord, D.L. (2002). PAUP 4.0b10a: Phylogenetic Analysis Using Parsimony (and Other Methods). Sinauer, Sunderland, Massachusetts, USA.

Swofford, D.L.; Olsen, G.J.; Waddel, P.J. \& Hillis, D.M. (1996). Phylogenetic inference, In D.M. Hillis, C. Moritz \& B.K. Mable (eds.) Molecular Systematics. Sinauer, Sunderland, Massachusetts, USA, pp. 407-514. 